\title{
Editorial
}

\section{Tonsillectomy: A Simple Surgical Procedure?}

\author{
B.N. Landis \\ Department of Otolaryngology, Head and Neck Surgery, Rhinology-Olfactology Unit, \\ University Hospital of Geneva, Geneva, Switzerland
}

The current controversial issue is focused on pediatric tonsillectomy, a surgical procedure that is learned early during specialist training and performed by almost all otolaryngologists worldwide. Besides being the most frequent ENT surgery, it is also one of the most frequently performed pediatric surgeries. Having said this, it becomes clear that tonsillectomy must be a simple procedure not reserved only for experienced academic surgeons. At first glance it is not clear if there are any controversial issues to discuss. However, surgery is not restricted to the technical procedure within the operating theater but is part of a larger concept including indication for, and success of this surgery. Analyses of complications as well as long-term results are further cornerstones to evaluate the utility of a surgical procedure. Having a closer look at the history of tonsillectomy, it becomes quickly clear that barely any other ENT surgery has undergone so many changes regarding the frequency, indication and technique as tonsillectomy did. Regarding technique and indications, a very nice overview is given in two of the articles in this issue by Hultcrantz and Ericsson [1] and Gysin [2]. While tonsillectomy started to be a surgery for recurrent infections, it has meanwhile become mainly indicated to treat sleep apnea. However, new entities such as idiopathic fever syndromes like PFAPA syndrome [3] or as recently reported even neuropsychological syndromes emerge as possible indications [4]. More interestingly, besides medical indications, specialist training [5] and geosocioeconomic factors seem to influence the indication for tonsillectomy [6]. Tonsillectomy rates are sometimes dramatically divergent from one country to the other [7]. Being a physician's or lawyer's child decreases, whereas having elevated insurance status or parents who had tonsillectomy increases the child's risk for this surgery [8,9]. Soft interpretation of surgical indications is not a problem restricted to tonsillectomy and can be found in most medical specialties [10]. However, pediatric tonsillectomy is particular in that it is an almost exclusive elective surgery, the decision is not taken by the patient himself and it holds a yet still debated rate of fatal or even lethal complications [11, 12]. Recent events in Austria, where several young children died from postoperative hemorrhage within a few months, showed how 
Landis: Tonsillectomy: A Simple Surgical Procedure?

quickly medical procedures can be discussed and debated by the media and politicians. As a consequence, the Austrian Pediatric and ENT Societies had to revise and tighten the guidelines for adenotonsillectomy up to the point that watchful waiting or tonsillotomy has to be considered first, and be preferred over tonsillectomy whenever possible [13]. In light of all these aspects, it is our specialists' duty to continuously reconsider our current practice in order to decrease the complications and increase the patient's safety before such issues are required by the politicians due to public opinion or financial pressures. Considering the Austrian events, it should be discussed whether anonymous national reporting systems for major tonsillectomy complications would be helpful in preventing the specialist societies to be accused of carelessness. Although such registers would not directly decrease the complication rates, they may show our concern about the fate of our patients, and in the long term potential sources of complications might be identified. The systematic investigation of all Austrian tonsillectomies during a 1-year period just after the tragic events showed a surprisingly high rate of return to theater due to tonsillectomy hemorrhage [14]. Keeping a check on our work before the insurance companies do so might further strengthen our situation when it comes to financial debates.

Tonsillectomy is without any doubt an important and, in many cases, a beneficial surgery for the patients. However, future efforts should be directed towards the identification of clearer and less surgeon-dependent criteria for tonsillectomy. The surgical act itself is rather simple but the associated concerns such as indication, detailed technique, anesthesia, medication, duration of in-hospital stay and medical but also social handling of severe complications require experience. These considerations show that pediatric tonsillectomy is not only a special, but also a complex and by far not simple surgical procedure. The goal of the present issue was to discuss the advantages of tonsillectomy, but also to focus particularly on open questions and measures which could improve the patient's safety.

\section{References}

1 Hultcrantz E, Ericsson E: Factors influencing the indication for tonsillectomy: a historical overview and current concepts. ORL J Otorhinolaryngol Relat Spec 2013;75:184-191.

2 Gysin C: Indications for tonsillectomy. ORL J Otorhinolaryngol Relat Spec 2013;75:193-202.

-3 Garavello W, Romagnoli M, Gaini RM: Effectiveness of adenotonsillectomy in PFAPA syndrome: a randomized study. J Pediatr 2009;155:250-253.

4 Alexander AA, et al: Pediatric autoimmune neuropsychiatric disorders associated with streptococcal infections (PANDAS): an indication for tonsillectomy. Int J Pediatr Otorhinolaryngol 2011;75:872-873.

5 Faramarzi A, et al: Assessment of the consensus about tonsillectomy and/or adenoidectomy among pediatricians and otolaryngologists. Int J Pediatr Otorhinolaryngol 2010;74:133-136.

6 Croxford R, Friedberg J, Coyte PC: Socio-economic status and surgery in children: myringotomies and tonsillectomies in Ontario, Canada, 1996-2000. Acta Paediatr 2004;93:1245-1250.

-7 Van den Akker EH, et al: Large international differences in (adeno)tonsillectomy rates. Clin Otolaryngol Allied Sci 2004;29:161-164.

8 Fergusson DM, Horwood LJ: Private medical insurance and elective surgery during early childhood. NZ Med J 1985;98:538-540.

9 Domenighetti G, Bisig BE: Tonsillectomy: a family-transmissible surgical procedure. Lancet 1995;346:1376.

10 Domenighetti G, Casabianca A: Rate of hysterectomy is lower among female doctors and lawyers' wives. $\mathrm{Br}$ Med J 1997;314:1417.

11 Windfuhr JP, et al: Lethal outcome of post-tonsillectomy hemorrhage. Eur Arch Otorhinolaryngol 2008;265: 1527-1534.

12 Lowe D, van der Meulen J: Tonsillectomy technique as a risk factor for postoperative haemorrhage. Lancet 2004;364:697-702.

13 Gemeinsame Empfehlung der Österreichischen Gesellschaften für Hals-Nasen-Ohren-Heilkunde, Kopf- und Halschirurgie und Kinder- und Jugendheilkunde zur Entfernung der Gaumenmandeln (Tonsillektomie). November 9, 2007, pp 1-15.

14 Sarny S, et al: Hemorrhage following tonsil surgery: a multicenter prospective study. Laryngoscope 2011;121: 2553-2560. 